УДК 65.013

\title{
ОСНОВНЫЕ ЭКОНОМИКО-ТЕОРЕТИЧЕСКИЕ ПОДХОДЫ К ИССЛЕДОВАНИЮ ОРГАНИЗАЦИОННОЙ КУЛЬТУРЫ
}

\author{
Столяров Никита Олегович \\ Аспирант \\ Научный руководитель: Петренко Елена Степановна \\ д.э.Н., профессор \\ ФГБОУ ВО «Российский экономический университет \\ имени Г. В. Плеханова»
}

\begin{abstract}
Аннотация: в статье систематизированы основные подходы к исследованию организационной культуры управления субъектов хозяйствования. Особое внимание уделяется особенностям анализа организационной культуры в рамках неоинституциональной экономической теории. Показана необходимость синтетического использования положений различных школ и направлений экономической мысли при исследовании организационной культуры современных компаний.
\end{abstract}

Ключевые слова: организационная культура, организационные отношения, неоклассическая экономическая теория, институционализм, неоинституционализм.

\section{BASIC ECONOMIC AND THEORETICAL APPROACHES TO THE STUDY OF ORGANIZATIONAL CULTURE}

\section{Stolyarov Nikita Olegovich Scientific adviser: Petrenko Elena Stepanovna}

\begin{abstract}
The article systematizes the main approaches to the study of the organizational culture of management of economic entities. Special attention is paid to the peculiarities of the analysis of organizational culture in the framework of neoinstitutional economic theory. The necessity of synthetic use of the provisions of various schools and directions of economic thought in the study of the organizational culture of modern companies is shown.
\end{abstract}


Key words: organizational culture, organizational relations, neoclassical economic theory, institutionalism, neo-institutionalism.

Вопросами управления организационной культурой компаний занимались представители различных школ и направлений экономической науки. Основные подходы в данной области систематизированы в таблице 1.

Таблица 1

Особенности рассмотрения организационной культуры управления в рамках основных школ и направлений экономической мысли (систематизировано автором)

\begin{tabular}{|c|c|c|}
\hline $\begin{array}{c}\text { Школа или } \\
\text { направление } \\
\text { экономическо } \\
\text { й мысли }\end{array}$ & Основные представители & $\begin{array}{c}\text { Особенности анализа организационной } \\
\text { культуры управления }\end{array}$ \\
\hline \multicolumn{2}{|c|}{ 1. Экономическая теория К. Маркса } & $\begin{array}{l}\text { Отрицалась возможность какой-либо } \\
\text { производственной культуры в условиях } \\
\text { капиталистического способа } \\
\text { производства, генерирования } \\
\text { прибавочной стоимости, высокого } \\
\text { уровня эксплуатации наемного труда, } \\
\text { неудовлетворительных условий труда. }\end{array}$ \\
\hline $\begin{array}{l}2 . \\
\text { Неоклассичес } \\
\text { кая парадигма }\end{array}$ & $\begin{array}{l}\text { Дж. Кейнс, Дж. Хикс, } \\
\text { Г. Менш, Р. Солоу, } \\
\text { П. Самуэльсон, Н. Калдор, } \\
\text { Р.Харрод, А. Файоль, } \\
\text { Ф. Тэйлор. }\end{array}$ & $\begin{array}{l}\text { Выделение формирования } \\
\text { организационной культуры как одного } \\
\text { из принципов эффективного управления } \\
\text { (А. Файоль). Сугубо технократический } \\
\text { подход к пониманию организационной } \\
\text { культуры. Отсутствие системного } \\
\text { анализа структуры организационной } \\
\text { культуры управления и факторов ее } \\
\text { динамики. }\end{array}$ \\
\hline $\begin{array}{l}3 . \\
\text { Институциона } \\
\text { лизм }\end{array}$ & $\begin{array}{l}\text { Т. Веблен, Дж. Коммонс, } \\
\text { Дж. Гэлбрейт, М. Митчелл, } \\
\text { Ф. Ландберг }\end{array}$ & $\begin{array}{l}\text { Анализ влияния системы формальных и } \\
\text { неформальных норм и институтов на } \\
\text { процессы развития и } \\
\text { совершенствования организационной } \\
\text { культуры управления. }\end{array}$ \\
\hline $\begin{array}{l}4 . \\
\text { Неоинституци } \\
\text { онализм }\end{array}$ & $\begin{array}{l}\text { Р. Коуз, О. Уильямсон, } \\
\text { Д. Норт, Г. Гроссман, } \\
\text { Дж. Себастиан, Г. Саймон }\end{array}$ & $\begin{array}{l}\text { Рассмотрение особенностей } \\
\text { организационной культуры управления } \\
\text { с позиции теории игр, теории } \\
\text { трансакционных издержек, теории }\end{array}$ \\
\hline
\end{tabular}




\begin{tabular}{|c|c|c|}
\hline & & $\begin{array}{l}\text { отраслевых рынков, теории } \\
\text { организационных контрактов и др. } \\
\text { Развитие социально-психологического } \\
\text { подхода к исследованию } \\
\text { организационной культуры. }\end{array}$ \\
\hline $\begin{array}{l}5 . \\
\text { Экономическа } \\
\text { я наука СССР }\end{array}$ & $\begin{array}{l}\text { В.С. Немчинов, } \\
\text { Л.В. Канторович, } \\
\text { Л.И Абалкин, } \\
\text { К.В. Островитянов, } \\
\text { А.В. Дорохов и др. }\end{array}$ & $\begin{array}{l}\text { Непосредственно понятие } \\
\text { “организационная культура” не } \\
\text { использовалось. Тем не менее, имели } \\
\text { место процессы теоретического } \\
\text { обоснования и широкой апробации } \\
\text { таких факторов ее обеспечения в } \\
\text { плановой экономике, как } \\
\text { социалистические соревнования, } \\
\text { субботники, системы морального } \\
\text { поощрения труда и др. }\end{array}$ \\
\hline $\begin{array}{l}6 . \\
\text { Постнеокласс } \\
\text { ическая } \\
\text { парадигма }\end{array}$ & $\begin{array}{l}\text { И. Ансофф, И. Адизес, } \\
\text { Г. Хакен, Г. Бэккер, } \\
\text { И.Р. Пригожин, М. Портер, } \\
\text { Ф. Котлер, А.Б. Крейг, } \\
\text { Р. Каплан, Д. Нортон, Ф. Лалу } \\
\text { и др. }\end{array}$ & $\begin{array}{l}\text { Комплексное исследование } \\
\text { организационной культуры как одного } \\
\text { из основных факторов стратегического } \\
\text { развития. Рассмотрение отдельных } \\
\text { особенностей развития } \\
\text { организационной культуры в рамках } \\
\text { концепции т.н. “бирюзовых } \\
\text { организаций”. Развитие } \\
\text { синергетического подхода к } \\
\text { исследованию организационной } \\
\text { культуры управления. }\end{array}$ \\
\hline
\end{tabular}

Как показано в таблице 1 , негативистский подход к пониманию организационной культуры компаний впервые сформулировал К. Маркс. По его мнению, негативный социально-психологический климат в трудовых коллективах предприятий является прямым следствием неоправданно высокой эксплуатации наемного труда и непосредственно вытекающих из нее распространенных неудовлетворительных условий осуществления трудовой деятельности [1, с.329]. При этом вариантов решения данной проблемы в рамках капиталистической общественно-экономической формации Маркс не видел.

Основы позитивистского подхода к пониманию организационной культуры управления сформировал один из основоположников административной школы менеджмента, формально относящейся к 


\section{СОВРЕМЕННЫЕ ТЕХНОЛОГИИ:

неоклассической парадигме экономической мысли, А. Файоль [2, с.31]. Так, одним из принципов управления Файоля является т.н. “корпоративный дух" (внутриорганизационные ценности, ориентированные на обеспечение сплоченности сотрудников предприятия в процессе организации и осуществления трудовой деятельности), который вполне можно рассматривать в качестве определенного прообраза организационной культуры в современном понимании исследуемого понятия. При этом А. Файоль указывал на необходимость обеспечения соответствия корпоративного духа и других тринадцати аргументированных им принципов эффективного менеджмента.

В парадигме институциональной и неоинституциональной экономики акцент осуществлялся как на исследовании влияния норм и институтов на характер формирования и развития организационной культуры управления, так и на социально-психологических характеристиках рассматриваемого нами экономического явления. Так, один из ведущих представителей традиционного институционализма Дж.К. Гэлбрейт рассматривал эффективную организационную культуру компании в качестве значимого фактора обеспечения устойчивости развития последней к различным типам институциональных изменений [3].

В системе координат неоинституциональной экономической науки сформирован широкий круг инструментов, которые могут быть использованы для разнопланового исследования тенденций и проблем управления организационной культурой компаний, а именно:

a) теория игр позволяет рассматривать возможные конфликтные, консенсусные и равновесные состояния (равновесия по Нэшу, по Паретов и др.) взаимодействия различных групп предприятия в процессе управления процессами формирования и совершенствования организационной культуры;

б) теория трансакционных издержек обеспечивает возможности исследования состава и структуры трансакционных затрат, связанных с различными аспектами управления организационной культурой, разрабатывать организационно-экономические мероприятия по рационализации их уровня;

в) теория контрактов позволяет анализировать процессы развития организационной культуры в качестве своеобразных форм неформальных внутриорганизационнных контрактных отношений, характер которых описывается определенными моделями неоинституционального плана; 
г) теория отраслевых рынков дает возможность исследования особенностей отраслевой дифференциации моделей управления организационной культурой компаний.

В рамках теории управления народнохозяйственными системами при социализме термин “организационная культура”, типичный для западной науки менеджмента, напрямую не использовался. Тем не менее, широко распространенное в социалистической экономике понятие “социальнопсихологический климат в трудовом коллективе” по своему содержанию тесно корреспондирует с понятием организационной культуры.

В рамках постнеоклассической парадигмы представлен широкий круг подходов к социально-психологическому исследованию тенденций и проблем развития организационной культуры и формированию научно обоснованных систем управления исследуемым процессом, стратегическому, в том числе синтергетическому, анализу организационной культуры, обоснованию возможностей интеграции показателей оргкультуры управления в состав сбалансированной системы показателей (ССП) деятельности компании и др.

Так, один из основоположников теории стратегического менеджмента, являющейся составной частью постнеоклассической парадигмы экономического анализа, И. Ансофф включал организационную культуру управления в состав наиболее значимых параметров развития стратегических зон хозяйствования (С3X) производственных компаний [4, с.57]. М. Портер учитывал параметры организационной культуры при формировании конкурентного профиля компании на отраслевых рынках товаров, работ, услуг [5, с.162]. И. Адизес рассматривал фактор возможности позитивно влиять в долгосрочной перспективе на формирование эффективной организационной культуры управления в качестве одной из ключевых компетенций современного руководителя [6, с.218].

Р. Каплан и Д. Нортон предлагают включать параметры организационной культуры в качестве одной из характеристик внутренних процессов развития компании в рамках сформированной ими методологии ССП [7, с.172]. Вместе с тем, указанные представители постнеоклассического направления экономической науки не конкретизируют состав конкретных показателей, характеризующих различные аспекты управления организационной культурой, а также алгоритм их балансировки с другими блоками показателей развития компании, такими как блок рыночной позиции, блок финансовой деятельности и блок инновационной активности. 
В целом, в практике анализа организационной культуры современных компаний, по мнению автора, следует использовать синтез методического инструментария различных школ и направлений экономической науки, в первую очередь экономики неоинституционализма и постнеоклассической экономической теории.

\section{Список литературы}

1. Маркс К. Капитал. М.: Академия, 2020. Т1. - 512 с.

2. Файоль А. и др. Управление - это наука и искусство. М.: Республика, 1992. $-286 \mathrm{c}$.

3. Гэлбрейт Дж.К. Новое индустриальное общество [Электронный pecypc]. Режим доступа: https://gtmarket.ru/laboratory/basis/5021 (дата обращения 24.03.2021).

4. Ансофф И. Новая корпоративная стратегия. - М.: Дело и сервис, 2011. $-434 \mathrm{c.}$.

5. Портер М. Конкурентная стратегия. Методика анализа отраслей и конкурентов. - М.: Альпина Паблишер, 2018. - 482 с.

6. Адизес И. Управление жизненным циклом корпораций. - М.: Манн, Иванов и Фербер, 2015. - 320 с.

7. Каплан Р., Нортон Д. Стратегические карты. - М.: Альпина Паблишер, 2020. - 384 с. 